\title{
Superando a liability of outsidership na China: A experiência das empresas brasileiras no desenvolvimento do guanxi
}

\author{
Janaina Mortari Schiavini ${ }^{1 A}$ e Flavia Luciane Scherer ${ }^{B}$ \\ ${ }^{A}$ Universidade Federal do Pampa-UFP, Bagé, RS, Brasil. \\ ${ }^{B}$ Universidade Federal de Santa Maria - UFSM, Santa Maria, RS, Brasil.
}

DETALHES DO ARTÍGO
Histórico do Artigo:
Recebido em 25 de Agosto de 2014
Aceito em 01 de Julho de 2015
Disponível online em 19 de Dezembro de 2015
Sistema de Revisão "Double Blind Review"
Editor Científico
Felipe Mendes Borini

\section{Palavras-chaves:}

Internacionalização

Liability of Outsidership

Guanxi

Redes

China

\begin{abstract}
RESUMO
À luz das discussões sobre internacionalização de empresas, uma abordagem teórica defende que as principais barreiras no processo de internacionalização estão relacionadas ao ônus de estar fora das redes de relacionamento internacionais, ou seja, enfrentam a chamada liability of outsidership. Considerando a relevância da China para o Brasil e a complexidade das relações de negócios no país (guanxi), este estudo se propôs a investigar como empresas brasileiras que operam na China desenvolvem guanxi como meio de superar a liability of outsidership, com base no modelo teórico de Chen e Chen (2004). Foi desenvolvida uma pesquisa descritiva e qualitativa, sendo realizado um estudo de casos múltiplos em quatro empresas brasileiras do setor de serviços que possuem filial na China. A coleta de dados ocorreu por meio de entrevistas semi-estruturadas. Para o tratamento dos dados, optou-se pela análise de conteúdo, com o auxílio do software NVivo 8.0. Os resultados identificaram as motivações na internacionalização para a China, as dificuldades enfrentadas decorrentes da liability of outsidership, a importância e os benefícios do guanxi, e as atividades realizadas para o seu desenvolvimento. Espera-se que este trabalho contribua para geração de conhecimento sobre a internacionalização das empresas brasileiras para a China.
\end{abstract}

(C) 2015 Internext | ESPM. Todos os direitos reservados!

\section{Introdução}

Os estudos sobre a internacionalização de empresas vêm ganhando cada vez mais relevância, devido não somente aos impulsos da globalização, mas também ao crescente movimento de empresas brasileiras que buscam obter vantagens competitivas por meio de sua inserção no mercado estrangeiro. A busca por compreender o Brasil e sua inserção no cenário internacional tem sido um tema relevante para muitos pesquisadores, assim como os investimentos diretos estrangeiros (IDE) realizados no país (FLEURY; FLEURY, 2007).

De acordo com Fleury e Fleury (2012), foi somente a partir do final do século $X X$ que a internacionalização das empresas brasileiras ganhou ritmo e consistência. O desenvolvimento político, econômico e social do Brasil desde o período colonial até o final dos anos 1980 formaram o contexto em que as multinacionais brasileiras emergiram. A competição entre as empresas brasileiras e as subsidiárias de empresas estrangeiras, inseridas em um ambiente caracterizado pela incerteza e descontinuidade, criaram condições para o desenvolvimento de competências que impulsionaram a internacionalização das empresas brasileiras (FLEURY; FLEURY, 2012).

O Brasil, juntamente com os outros países BRIC (Brasil, Rússia, Índia e China), tem assumido importância cada vez maior no âmbito global e na sua estrutura de poder, passando a impactar as relações econômicas mundiais. Diante deste cenário, o Brasil vem estreitando suas relações com a China, sua principal parceira comercial em importação e exportação. Porém, a internacionalização para a 
China pode, em alguns casos, ser considerada extremamente complexa, sendo as diferenças culturais um aspecto importante.

Para Johanson e Vahlne (1977), a cultura dos países é considerada uma das grandes barreiras no processo de internacionalização. Entretanto, os problemas e oportunidades que podem ocorrer para uma empresa em seu processo de internacionalização também estão relacionados ao fato de as empresas estarem ou não inseridas em redes de relacionamentos (JOHANSON; VAHLNE, 2009). Ou seja, os autores perceberam que a liability of outsidership, que significa a desvantagem de não estar inserida em redes de relacionamentos tanto no mercado doméstico quanto no internacional, também impacta no processo de internacionalização de empresas.

Neste sentido, existe um importante traço cultural na China que valoriza intensamente os relacionamentos, sendo a base das relações sociais no país. Este traço é conhecido como guanxi. De acordo com Bell (2000), guanxi é uma rede de relações que se inicia no âmbito familiar e se expande para outras esferas de relacionamento que se estabelecem ao longo da vida das pessoas. É um tipo especial de relação que une os parceiros por meio de obrigações recíprocas para obtenção de recursos através de uma cooperação contínua e troca de favores (CHEN, 1995). A moderna sociedade chinesa ainda opera dentro dos domínios dessas inúmeras redes de guanxi sociais e empresariais. Assim, é fundamental para as empresas na China, sejam locais ou estrangeiras, compreender e utilizar corretamente o guanxi para ganhar vantagens sobre os concorrentes.

Considerando a relevância do mercado asiático para o Brasil, o Conselho Empresarial Brasil-China realizou uma pesquisa que mapeou a experiência das empresas brasileiras que internacionalizam seus negócios para China (CEBC, 2012). Os resultados mostraram que a distância física e cultural com o Brasil, as peculiaridades do ambiente de negócios chinês e a falta de conhecimento sobre como lidar com as diversas instâncias do governo chinês foram as principais barreiras enfrentadas pelas empresas brasileiras. Para contornar estes desafios, as empresas adotaram estratégias como: (1) estabelecimento de uma rede guanxi e (2) associação com uma empresa chinesa.
A partir do exposto, este estudo tem como objetivo investigar como as empresas brasileiras que internacionalizaram para a China têm desenvolvido guanxi como meio de superar a liability of outsidership. Além disso, pretende-se compreender a importância do guanxi para as empresas estudadas e os benefícios que esta rede oferece dentro no mercado asiático. Com base nesta finalidade, o presente estudo teve como base o modelo teórico de Chen e Chen (2004), em que os autores argumentam que o guanxi pode ser desenvolvido por meio de três fases, evidenciando os objetivos e principais fundamentos em cada uma delas.

\section{Referencial teórico \\ 2.1 Liability of Outsidership}

O Modelo de Upssala de 1977 (JOHANSON; VAHLNE, 1977), que trata da internacionalização de empresas como um processo incremental, tem como pressupostos a incerteza e racionalidade limitada (PENROSE, 1959; CYERT; MARCH, 1963; AHARONI 1966). À luz das discussões de Johanson e Vahlne (1977), uma maior distância psíquica implicaria um maior grau de liability of foreignness, ou seja, o custo ou desvantagem de operar em mercados estrangeiros. Simplificando, as empresas precisariam ter uma vantagem específica da organização para compensar as dificuldades pelo fato de ser uma empresa estrangeira explorando novos mercados fora do seu país de origem.

Em uma fase posterior, com o advento das redes de relacionamento, o foco passa a ser a empresa, situada em um ambiente, imersa nestas redes (HOLM; ERIKSSON; JOHANSON, 1996; ERIKSSON et. al, 1997; JOHANSON; VAHLNE, 2003; 2009). O argumento principal é baseado no mercado como sendo uma rede de relacionamentos em que as empresas estão ligadas umas às outras por meio de padrões complexos, variados e em grande medida, invisíveis. Assim, o fato de estar dentro (insider), ou seja, pertencer a uma rede relevante é necessário para uma internacionalização bem sucedida. Da mesma forma, estar fora (outsider) é um ônus para o processo. Em segundo lugar, as relações oferecem um potencial para o aprendizado e para a construção da confiança e do comprometimento, ambos entendidos como pré condições para a internacionalização (JOHANSON; VAHLNE, 2009).

Johanson e Vahlne (2009) argumentam que se a liability of foreignness é um problema de 
internacionalização, a liability of outsidership pode ser uma dificuldade tanto para mercados internacionais quanto ao mercado doméstico. Da mesma forma que é necessário fazer parte de uma rede de negócios e desfrutar de relacionamentos no mercado doméstico, é essencial inserir-se nas redes de relacionamento em mercados estrangeiros para ser bem sucedido no processo de internacionalização (JOHANSON; VAHLNE, 2009).

Atualmente, o modelo de Uppsala mantém o foco nas redes de relacionamento juntamente com o reconhecimento do papel dos empreendedores na formação e manutenção desses relacionamentos (SCHWEIZER et al, 2010). A capacidade empreendedora é uma variável importante, pois entende-se que o empresário que toma as decisões de internacionalização é influenciado por características idiossincráticas, com capacidades tanto emocionais quanto intelectuais, sendo a aprendizagem experiencial um fator importante para estas decisões.

Neste sentido, é possível pressupor que a questão "onde internacionalizar", em que a distância psíquica e a liability of foreignness eram consideradas influentes, pode torna-se uma questão de "com quem internacionalizar", uma vez que a liability of outsidership parece ser o novo ponto crucial no processo da internacionalização. As empresas, principalmente de países emergentes, não seguem mais a regra do gradualismo, tanto em termos de distância psíquica quanto nos modos de entrada. Mathews (2006) defende que as características inovadoras que estas multinacionais compartilham, tais como a sua internacionalização acelerada, a inovação estratégica e inovação organizacional, se encaixam particularmente bem com as características das economias emergentes em uma complexa ligação interorganizacional.

Assim, Mathews (2006) fez um estudo com empresas chinesas, e percebeu que elas seguiam um padrão de trajetória de internacionalização que chamou de LLL (Linkage, Leverage, Learning).

Linkage refere-se às vantagens que as empresas podem adquirir externamente, ou seja, "a orientação global se torna uma fonte de vantagem provável de ser encontrada no mercado global ao invés do ambiente doméstico" (MATHEWS, 2006, p. 18). O autor cita como exemplo as empresas chinesas que firmaram joint ventures com empresas taiwanesas para obtenção tecnologia. Leverage está relacionado a parcerias que as empresas chinesas realizaram com empresas multinacionais para melhorar o nível e o rendimento dos recursos que foram adquiridos por meio do linkage. O foco está direcionado para os recursos próprios, e seu potencial de alavancagem. $\mathrm{E}$ learning consiste no aprendizado organizacional por meio da repetição de diversas relações de linkage e de leverage. As empresas aprendem a desenvolver novos produtos e serviços mais rapidamente depois de ter adquirido conhecimento nas relações para aquisição de recursos (Linkage) e melhoria do nível desses recursos (Leverage).

Assim, as redes de negócios vieram para desafiar as discussões sobre os modelos de internacionalização, acrescentando o fato de que os negócios são feitos por pessoas e, por isso, as relações interpessoais estão envolvidas (KARIMIBABAK; SINCLAIR, 2011). As empresas podem mover-se e internacionalizar rapidamente e, principalmente, se adaptar mais rápido, devido a um link direto com as redes de negócios no novo ambiente.

Holm, Eriksson e Johanson (1996) têm destacado as redes internacionais como competências importantes para a obtenção de resultados positivos em empresas internacionalizadas. A prática de estabelecer relacionamentos com parceiros estrangeiros em detrimento do investimento direto em estágios iniciais do processo de internacionalização tem sido adotada por diversas empresas, principalmente aquelas que optam pelo baixo comprometimento de ativos no mercado internacional.

\subsection{Guanxi}

Embora guanxi não possa ser literalmente traduzido como "rede", tal qual o termo é conceituado no Ocidente, existe uma série de características que podem classificar este relacionamento como uma rede. É um conceito que está incorporado ao confucionismo e tem sua própria lógica na formação e constituição da estrutura da sociedade chinesa (LUO, 2001).

Para entender o intrincado processo de relacionamento do guanxi, faz-se necessário compreender a maneira como ele se estruturou ao longo do tempo. A China, mesmo com o enorme crescimento econômico e industrialização obtidos nas últimas décadas, ainda possui a maior parte de sua população no campo, com significativa atividade 
ligada à agricultura e adjacentes. Tendo uma geografia pouco favorável ao uso intensivo da terra, a população chinesa sempre enfrentou o desafio de plantar e colher alimento em grande quantidade a fim de enfrentar as intempéries naturais, calamidades sociais e garantir a sobrevivência de uma população cada vez maior, com o mesmo pedaço de terra (FAIRBANK; GOLDMAN, 2007). Por isso, um chinês nunca é incentivado a pensar ou agir de maneira individualista e nunca é tratado como uma entidade isolada. Enquanto os ocidentais parecem se pautar na premissa de que "todos nascem iguais", os chineses acreditam que "todos nascem conectados" (HAIHUA; BAKER, 2008).

Este contexto, marcado pela luta incessante pela sobrevivência, foi o berço do guanxi, em que a dependência sobre a família muitas vezes não era suficiente, e uma extensão, para além dos laços familiares de apoio, foi demandada por meio da participação da aldeia, grupo de trabalho, ou grupo de parentesco. Especificamente o método chinês de articular esta extensão do apoio familiar para além da família doméstica é denominado guanxi (BELL, 2000).

Na atualidade, guanxi é usado nas mais diversas atividades e ainda tem profunda influência na cultura dos chineses e seus descendentes, tanto nos negócios, quanto nos relacionamentos pessoais e familiares. Neste sentido, o fator confiança (xinyon) é essencial na constituição do guanxi. Se os negócios são feitos com pessoas de confiança, não há contratos ou regras formais. Essas passam a ser aplicadas se a contraparte não faz parte da família ou não compõe a rede de confiança (KAO, 1991). Tendo isso em mente, quando se lida com os chineses, as empresas estrangeiras devem considerar a confiança como uma prioridade máxima em suas relações comerciais, pois se não há confiança, o contrato formalizado é desprovido de sentido.

Uma questão importante de ser esclarecida é: o guanxi acontece entre indivíduos ou organizações? Standifird (2006) garante que o guanxi é fundamentalmente uma relação entre indivíduos, mas que podem ser transformadas em vantagem competitiva para a organização. O guanxi se torna um ativo organizacional apenas na medida em que os indivíduos estão dispostos a usar o seu guanxi em nome da organização (STANDIFIRD, 2006). A existência de funcionários altamente ligados pode ter um efeito multiplicador na medida em que estão conectados um ao outro. As organizações devem apoiar explicitamente o desenvolvimento de guanxi entre os indivíduos, pois a sua reputação cresce na medida em que os seus funcionários estão bem conectados (tanto externa como internamente) e na medida em que essas conexões tornam-se associadas a importantes resultados organizacionais.

\subsection{Como desenvolver guanxi}

A crescente aceitação e popularidade do guanxi no Ocidente tornaram ainda mais importante a compreensão conceitual desse fenômeno, motivando pesquisadores a analisar o seu impacto no desempenho e relacionamento da empresa e propor modelos sobre como desenvolver o guanxi. A pesquisa realizada por Chen e Chen (2004) sobre a construção do guanxi tem sido uma das obras mais relevantes sobre o assunto.

Os autores propõem o desenvolvimento do guanxi de acordo com três etapas: (1) início, (2) construção e (3) uso. A Figura 1 apresenta os três conjuntos de variáveis por etapa, apresentando inicialmente uma concepção integrada para desenvolver guanxi.

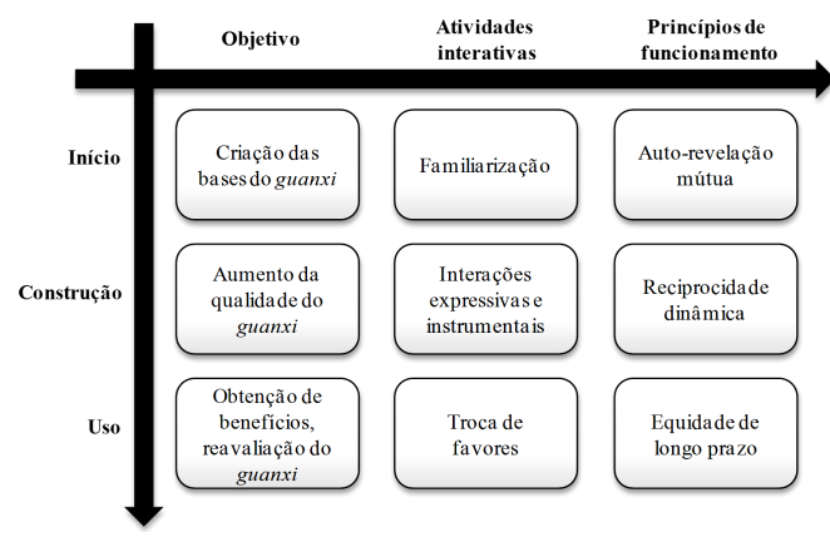

Figura 1: Processo de desenvolvimento do guanxi Fonte: Adaptado de Chen e Chen (2004, p. 310)

Durante a primeira fase, dois indivíduos se familiarizam um com o outro por meio de uma autorevelação mútua. Neste processo, as duas partes buscam identificar pontos em comum - a criação das bases do guanxi. Chen e Chen (2004) alertam que as pessoas de culturas orientais, incluindo o chinês, não "quebram o gelo" facilmente com estranhos e não são tão socialmente desenvolvidos como os ocidentais, que rapidamente estabelecem contato com pessoas que não conhecem. Portanto, como um gesto de desejo em começar o relacionamento, as partes têm que mostrar vontade mútua de se autodivulgar, como se fossem velhos amigos (CHEN; CHEN, 2004). Dado o desejo de estabelecer bases para o futuro guanxi, a reciprocidade é um 
complemento essencial para a iniciativa de autorevelação. Em qualquer caso, quanto maior a autorevelação mútua, melhor a criação das bases do guanxi.

Uma iniciação bem sucedida leva para a segunda fase - a construção do guanxi. De acordo com Chen e Chen (2004), o objetivo desta etapa é estabelecer a confiança mútua e o afeto para construir guanxi de qualidade. As atividades desta etapa baseiam-se em interações expressivas e instrumentais. As interações expressivas referem-se a atividades sociais como festas, celebração de casamentos, nascimentos, aniversários, etc. As instrumentais estão relacionadas a atividades pragmáticas de trabalho e negócios, como ajuda mútua em encontrar emprego, atribuição de trabalho, troca de informações, cooperação local de trabalho, transações comerciais, etc. Estes dois tipos de interações visam aproximação, ou seja, melhorar a qualidade do guanxi em termos de construção da confiança, afeto e a reciprocidade.

Após construído o guanxi, torna-se possível beneficiar-se do seu uso. Esta etapa é marcada pela troca de favores regulada pelo princípio da equidade de longo prazo. Este princípio defende que os indivíduos em uma situação de troca têm direito de partilhar o seu resultado de acordo com a sua contribuição no processo de troca. É possível que uma das partes peça a ajuda da outra parte continuamente por várias vezes, mas até mesmo entre amigos íntimos e parentes, os esforços são feitos para lembrar conscientemente e manter o balanço social em equilíbrio no longo prazo (YANG, 1994).

Se um favor concedido de "A" para "B" excede as expectativas de " $B$ ", então " $A$ " terá um senso de equidade e o nível de qualidade guanxi será mantido ou melhorado. No entanto, quando um favor não é concedido conforme a expectativa, haverá um sentimento de desigualdade e a qualidade guanxi poderá ser prejudicada. Quando o resultado real é inferior a expectativa, pode haver uma sensação de traição e as duas partes poderão se afastar. A fim de proteger a qualidade do guanxi, o indivíduo que não conseguiu dar o favor pedido, muitas vezes tenta provar o seu desejo ou sua relação de continuidade, proporcionando favores de outras formas ou em tempos futuros.

O modelo de Chen e Chen (2004) pode ser considerado um avanço significativo com relação às pesquisas sobre guanxi, pois retrata este fenômeno como um processo dinâmico e de possível desenvolvimento, mesmo para os ocidentais. A diferenciação dos atributos do guanxi não só facilita a sua construção, como também contribui para examinar os seus efeitos no relacionamento entre indivíduos e organizações.

\subsection{Referencial analítico}

Considerando o objetivo desta pesquisa, a perspectiva comportamental, que considera as redes de negócios no processo de internacionalização (JOHANSON; VAHLNE, 1977; 2009), pareceu ser a mais adequada, pois aborda dois aspectos importantes que configuram algumas das barreiras na internacionalização: a distância psíquica e a liability of outsidership. Sabendo que as redes de relacionamento são capazes de fornecer informações que facilitam a identificação de oportunidades de negócios, diminuindo os riscos e incertezas do ambiente em que a empresa está inserida, elas podem ser consideradas uma forma de superação a estas barreiras.

Uma vez que o objeto deste estudo são as empresas brasileiras que internacionalizaram para a China, a barreira da distância psíquica é ainda mais alta. De acordo com o estudo realizado por Silva, Rocha e Figueiredo (2007), a China é o segundo país com maior distância psíquica com o Brasil, ficando atrás apenas do Japão.

Da mesma forma, a liability of outsidership tornase um grande entrave para as empresas estrangeiras que ainda são ousiders nas redes de relacionamento do mercado asiático (guanxi). Além disso, a forma de inserir-se nestas redes difere consideravelmente da maneira como este processo é conduzido nos países ocidentais, por exemplo. Na China, os relacionamentos são essencialmente baseados entre os indivíduos, e não entre organizações. A linha que separa a vida profissional da pessoal é extremamente tênue. Por isso, o desenvolvimento do guanxi tornase um desafio para as empresas estrangeiras na China, mas também uma das chaves para o sucesso da internacionalização no país.

Portanto, compreender como as empresas brasileiras que operam na China tem desenvolvido guanxi como meio de superar a liability of outsidership tornou-se o problema desta pesquisa. Considerando a literatura consultada, foi possível esquematizar o referencial teórico (Figura 2) e as possíveis relações entre os construtos: (1) 
Tabela 1

Perfil das empresas estudadas

\begin{tabular}{|c|c|c|c|c|}
\hline Perfil da empresa & Empresa A1 & Empresa A2 & Empresa T1 & Empresa T2 \\
\hline Ano de fundação & 1958 & 1978 & 1973 & 2004 \\
\hline Ramo de atuação & \multicolumn{2}{|c|}{ Escritório de advocacia } & \multicolumn{2}{|c|}{ Trading } \\
\hline Principais serviços & \multicolumn{2}{|c|}{ Assessoria jurídica nacional e internacional } & \multicolumn{2}{|c|}{ Operações de importação e exportação } \\
\hline Receita bruta anual & Mais de 300 milhões & Mais de 300 milhões & Mais de 300 milhões & De 90 a 300 milhões \\
\hline Matriz & São Paulo (SP) & São Paulo (SP) & São Paulo (SP) & Shangai (China) \\
\hline Presença no Brasil & Brasília (DF) & $\begin{array}{c}\text { Brasília (DF), Rio de } \\
\text { Janeiro (RJ), Curitiba } \\
\text { (PR), Recife (PE), Belo } \\
\text { Horizonte (MG) e } \\
\text { Campo Grande (MS) }\end{array}$ & $\begin{array}{c}\text { Americana (SP), Itajaí } \\
\text { (SC), Recife (PE) e } \\
\text { Vitória (ES) }\end{array}$ & São Paulo (SP) \\
\hline Presença no mundo & $\begin{array}{l}\text { Lisboa (Portugal), } \\
\text { Miami (EUA), Luanda } \\
\text { (África), Munique } \\
\text { (Alemanha) e Buenos } \\
\text { Aires (Argentina), } \\
\text { Beijing (China) }\end{array}$ & $\begin{array}{c}\text { Buenos Aires } \\
\text { (Argentina), Miami } \\
\text { (EUA), Londres, (Reino } \\
\text { Unido), Lisboa } \\
\text { (Portugal), } \\
\text { Johannesburgo (África } \\
\text { do Sul), Nova Delhi } \\
\text { (Índia), Shangai e } \\
\text { Beijing (China). }\end{array}$ & $\begin{array}{c}\text { Warsaw (Polônia), } \\
\text { Moscou (Rússia), } \\
\text { Shangai (China) }\end{array}$ & $\begin{array}{l}\text { Shangai (China), } \\
\text { Luanda (Angola) }\end{array}$ \\
\hline Ano entrada na China & 2003 & 2001 & 1980 & 2004 \\
\hline
\end{tabular}

Fonte: Elaborado pelos autores

internacionalização, (2) distância psíquica, (3) liability of outsidership e (4) guanxi.

\section{Internacionalização para China}

Empresas brasileiras que internacionalizaram para a China

Principais barreiras

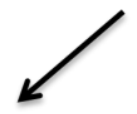

Distância psíquica

Alta distância psíquica entre Brasil e China

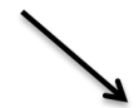

Liability of outsidership

Empresas ainda outsiders nas redes do mercado asiático

Forma de superação
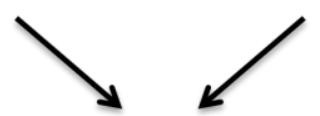

\section{Guanxi}

Base central das relações sociais na China. Tipo especial de relação que une os parceiros por meio de obrigações recíprocas.

\section{Problema de pesquisa}

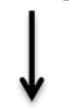

Como as empresas brasileiras que operam na China tem desenvolvido o guanxi como meio de superar a liability of outsidership?

Figura 2: Referencial analítico

Fonte: Elaborado pelos autores.

\section{Método de Pesquisa}

Este trabalho adotou um método de investigação qualitativa e caráter descritivo, uma vez que visa compreender os fenômenos estudados com base na visão dos próprios envolvidos na situação em um dado momento específico, ou seja, a internacionalização das empresas estudadas para a China.

A abordagem qualitativa também foi motivada por estudiosos da área de Negócios Internacionais e Gestão Internacional, que vêm encorajando os pesquisadores a utilizar métodos de pesquisa qualitativa com mais frequência. De acordo com Oesterle e Wolf (2011), a pesquisa qualitativa é necessária neste campo de estudos devido às muitas peculiaridades que não podem ser suficientemente capturadas por dados quantitativos, principalmente quando se referem às diferenças nos ambientes culturais e institucionais dos países.

Com relação à estratégia de pesquisa, foi realizado um estudo de casos múltiplos. De acordo com Gil (2009), os estudos de casos favorecem a acumulação de evidências acerca de fenômenos, à medida que estes são estudados em contextos diferentes.

Foram pesquisadas quatro empresas brasileiras que atuam no setor de serviços, sendo dois escritórios de advocacia e duas tradings. De acordo com a CEBC (2012), das 57 empresas brasileiras 
Tabela 2

Perfil dos entrevistados

\begin{tabular}{cll}
\hline Empresa & Cargo do Entrevistado & \multicolumn{1}{c}{ Experiência com a China } \\
\hline Empresa A1 & Advogado Sócio & $\begin{array}{l}\text { Atuou na filial da empresa na China por } 5 \text { anos (de 2007 a 2011) e continua atuando } \\
\text { com os clientes chineses no Brasil. }\end{array}$ \\
Empresa A2 & Diretor do setor China & $\begin{array}{l}\text { Advogado chinês, veio há } 5 \text { anos para o Brasil atuar como advogado principalmente } \\
\text { com os clientes chineses. }\end{array}$ \\
Empresa T1 & Gerente Comercial & $\begin{array}{l}\text { Atuou na filial da empresa na China por } 2 \text { anos (de } 2010 \text { a 2011) e continua atuando } \\
\text { com os clientes chineses no Brasil. }\end{array}$ \\
Empresa T2 & Sócio-Fundador (CEO) & $\begin{array}{l}\text { Atua no ramo de comércio exterior com a China há } 9 \text { anos e mora no país desde a } \\
\text { fundação da empresa (2004). }\end{array}$ \\
\hline
\end{tabular}

Fonte: Elaborado pelos autores

mapeadas na China, 50,9\% são prestadoras de serviços (escritórios de advocacia, tradings, consultorias de negócios, e bancos), sendo o principal setor de atuação as tradings (15,8\%). A opção por estudar estas quatro empresas obedeceu a dois critérios fundamentais: (1) ser empresa prestadora de serviços e que atue como intermediária entre empresas chinesas e brasileiras e (2) possuir filial na china.

De forma geral, as empresas selecionadas para este estudo possuem algumas características em comum, conforme resumido no Tabela 1 . Todas fazem parte do setor terciário e atendem principalmente pessoas jurídicas, ou seja, seus clientes também são empresas. Além disso, todas possuem filial na China e atuam como intermediárias entre as empresas chinesas e brasileiras, por meio da prestação de serviços de advocacia e de operações de comércio internacional.

Para coleta de dados, utilizaram-se dados de origem secundária para caracterizar as empresas e o seu processo de internacionalização, obtidos por meio do site institucional das empresas, material de divulgação, jornais internos, e trabalhos acadêmicos que descrevem esse processo. Os dados primários foram obtidos por meio de entrevistas semiestruturadas, exploradas em profundidade, com os profissionais que possuíam mais experiência na condução dos negócios da empresa com a China (Tabela 2). Foram realizadas quatro entrevistas, com duração média de 1 hora e 30 minutos, em julho de 2012.

Os dados originados das entrevistas foram examinados com base na análise de conteúdo (BARDIN, 2010), com o auxílio do software NVivo 8.0, por meio do qual foi possível identificar categorias, codificar, filtrar, fazer buscar e questionar os dados para responder às perguntas de investigação. A categorização a posteriori, estabelecida para a análise do conteúdo, encontra-se resumida no Tabela 3, que sintetiza os tipos de informações que foram pesquisadas em cada categoria e suas respectivas subcategorias. As categorias de análise foram definidas de acordo com o referencial analítico e o modelo de Chen e Chen (2004).

\section{Tabela 3}

Categorias e subcategorias de análise

\begin{tabular}{|c|c|}
\hline Categories & Subcategories \\
\hline I Interesses na China & $\begin{array}{l}\text { Razões para internacionalizar para China } \\
\text { Características dos serviços prestados e dos clientes no país }\end{array}$ \\
\hline II Significado, importância e impacto do guanxi & $\begin{array}{l}\text { Significado e importância } \\
\text { Benefícios e dificuldades (liability of outsidership) }\end{array}$ \\
\hline III Desenvolvimento do guanxi & Fase I: Início; Fase II: Construção; Fase III: Uso \\
\hline
\end{tabular}

Fonte: Elaborado pelos autores 
Tabela 4

Interesses na China das empresas estudadas

\begin{tabular}{|c|c|c|c|c|}
\hline Categoria 1 & Empresa A1 & Empresa A2 & Empresa T1 & Empresa T2 \\
\hline $\begin{array}{l}\text { Motivo da } \\
\text { internacionali-zação }\end{array}$ & $\begin{array}{c}\text { Facilitar e melhorar o } \\
\text { atendimento dos } \\
\text { clientes chineses. }\end{array}$ & $\begin{array}{l}\text { Representar os } \\
\text { interesses comerciais } \\
\text { dos chineses na } \\
\text { América do Sul. }\end{array}$ & $\begin{array}{c}\text { Facilitar a exportação } \\
\text { dos excedentes de } \\
\text { matérias-primas } \\
\text { têxteis do Brasil para a } \\
\text { China. }\end{array}$ & $\begin{array}{c}\text { Facilitar a exportação } \\
\text { de produtos chineses } \\
\text { para o Brasil. }\end{array}$ \\
\hline $\begin{array}{l}\text { Principais serviços } \\
\text { prestados no país }\end{array}$ & $\begin{array}{l}\text { Constituição de } \\
\text { empresas chinesas no } \\
\text { Brasil, fusões e } \\
\text { aquisições, elaboração } \\
\text { de contratos de } \\
\text { importação, } \\
\text { exportação e } \\
\text { distribuição, etc. }\end{array}$ & $\begin{array}{c}\text { Tradução das minutas } \\
\text { e registros de } \\
\text { contratos em } \\
\text { português, inglês e } \\
\text { mandarim, obtenção } \\
\text { de vistos, registros de } \\
\text { investimentos, licença } \\
\text { de marcas, etc. }\end{array}$ & $\begin{array}{l}\text { Importação de } \\
\text { produtos chineses para } \\
\text { o Brasil. Atividades de } \\
\text { sourcing, controle de } \\
\text { qualidade, e } \\
\text { acompanhamento das } \\
\text { operações. }\end{array}$ & $\begin{array}{c}\text { Exportação de } \\
\text { produtos chineses para } \\
\text { o Brasil. Controle do } \\
\text { processo de compra, } \\
\text { prospecção de } \\
\text { fornecedores, } \\
\text { embarque das } \\
\text { mercadorias. }\end{array}$ \\
\hline $\begin{array}{c}\text { Principais clientes } \\
\text { chineses }\end{array}$ & $\begin{array}{c}30 \text { clientes chineses, } \\
\text { sendo a maioria } \\
\text { empresa estatal. }\end{array}$ & $\begin{array}{c}\text { Mais de } 1000 \text { clientes } \\
\text { chineses. }\end{array}$ & $\begin{array}{l}\text { Não há clientes } \\
\text { chineses, apenas } \\
\text { fornecedores. }\end{array}$ & $\begin{array}{l}\text { Não há clientes } \\
\text { chineses, apenas } \\
\text { fornecedores. }\end{array}$ \\
\hline $\begin{array}{l}\text { Interesse dos clientes } \\
\text { chineses }\end{array}$ & $\begin{array}{c}\text { Segmentos de } \\
\text { siderurgia, construção } \\
\text { pesada, agricultura e } \\
\text { automotivo. }\end{array}$ & $\begin{array}{l}\text { Segmentos de energia } \\
\text { e agricultura, sendo } \\
\text { operações de comércio } \\
\text { exterior e joint } \\
\text { ventures. }\end{array}$ & - & 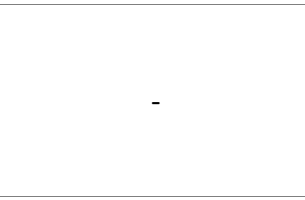 \\
\hline $\begin{array}{l}\text { Principais clientes } \\
\text { brasileiros na China }\end{array}$ & - & S & 20 a 30 empresas & $\begin{array}{l}45 \text { clientes brasileiros } \\
\text { de diversos segmentos }\end{array}$ \\
\hline $\begin{array}{l}\text { Interesse dos clientes } \\
\text { brasileiros na China }\end{array}$ & - & - & $\begin{array}{l}\text { Infra-estrutura na } \\
\text { China, garantindo o } \\
\text { sucesso da } \\
\text { importação. }\end{array}$ & $\begin{array}{c}\text { Compra de produtos } \\
\text { mais baratos para } \\
\text { revenda no Brasil. }\end{array}$ \\
\hline
\end{tabular}

Fonte: Elaborado pelos autores

\section{Apresentação e Análise dos Resultados}

Na primeira categoria de análise, que são os interesses das empresas estudadas na China, constam as principais motivações das empresas na internacionalização para a China (Tabela 4).

No caso das Empresas A1 e A2, a internacionalização para a China teve como objetivo facilitar o atendimento dos clientes e parceiros chineses que já vinham sendo atendidos, e buscar novas oportunidades no mercado asiático. Em ambos os casos, é possível identificar o resource seeking, que visa o acesso a recursos em condições mais vantajosas (DUNNING, 1988). Neste caso, as parcerias com organizações locais representaram o principal meio de entrada no mercado chinês.

Já as Empresas T1 e T2 apresentam características diferentes dos escritórios de advocacia. Para as tradings, a motivação está relacionada às condições favoráveis de localização da China. Ambas buscavam otimizar seus processos de exportação de produtos e reduzir os custos dos trâmites burocráticos das operações. De acordo com Dunning (1988), as vantagens de localização estão relacionadas à busca de benefícios como: recursos naturais, mão-de-obra, infra-estrutura, tamanho e características do mercado. Além disso, a proximidade com os fornecedores chineses agregou valor aos serviços prestados pelas tradings, uma vez que possibilitou um controle de qualidade e acompanhamento das operações mais eficiente.

Com relação à segunda categoria de análise, foram analisadas as percepções dos entrevistados quanto ao significado, a importância e os benefícios do guanxi, bem como as dificuldades enfrentadas decorrentes da liability of outsidership (Tabela 5).

O conceito de guanxi, de acordo com a literatura consultada, remete a palavras como "relacionamento", "relações", "rede", e "troca de favores" (YANG, 1994; CHEN, 1995; BELL, 2000). Nos quatro casos estudados, houve a menção destes termos quando questionou-se sobre o que significa guanxi, sendo que a palavra "relacionamento" ou "relações" esteve presente em todas. Assim, percebe-se um alinhamento entre o que a literatura apresenta e a forma como as empresas estudadas entendem como guanxi. 
Tabela 5

Significado do guanxi para as empresas estudadas

\begin{tabular}{|c|c|c|c|c|}
\hline Categoria 2 & Empresa A1 & Empresa A2 & Empresa T1 & Empresa T2 \\
\hline Significado & $\begin{array}{c}\text { Relacionamento } \\
\text { interpessoal, troca de } \\
\text { favores, rede de } \\
\text { contatos, corrupção, } \\
\text { crédito e débito de } \\
\text { favores. }\end{array}$ & $\begin{array}{l}\text { O mesmo que "relações } \\
\text { públicas" no ocidente. }\end{array}$ & $\begin{array}{c}\text { Relacionamento pessoal } \\
\text { com seus parceiros } \\
\text { comerciais. }\end{array}$ & Rede de contatos. \\
\hline $\begin{array}{l}\text { Diferenças entre guanxi } \\
\text { e os relacionamentos } \\
\text { ocidentais }\end{array}$ & $\begin{array}{l}\text { A diferença está na } \\
\text { intensidade }\end{array}$ & $\begin{array}{c}\text { A diferença está na } \\
\text { intensidade }\end{array}$ & $\begin{array}{l}\text { A diferença está na } \\
\text { intensidade }\end{array}$ & $\begin{array}{l}\text { Favorece os negócios } \\
\text { com os chineses. }\end{array}$ \\
\hline Importância & $\begin{array}{c}\text { Alta } \\
\text { Condição básica do } \\
\text { relacionamento } \\
\text { profissional para o } \\
\text { sucesso da empresa na } \\
\text { China. }\end{array}$ & $\begin{array}{c}\text { Alta } \\
\text { Guanxi gera confiança, } \\
\text { que é essencial para os } \\
\text { advogados. }\end{array}$ & $\begin{array}{c}\text { Alta } \\
\text { É estratégia da empresa } \\
\text { visitar os fornecedores } \\
\text { para fortalecer o } \\
\text { guanxi. }\end{array}$ & $\begin{array}{c}\text { Moderada } \\
\text { Não consideram apenas } \\
\text { o guanxi para buscar } \\
\text { resultados. }\end{array}$ \\
\hline $\begin{array}{l}\text { Investimento em } \\
\text { guanxi }\end{array}$ & $\begin{array}{c}\text { Pelo menos } 3 \text { visitas por } \\
\text { ano para a China. }\end{array}$ & $\begin{array}{c}\text { Participação em } \\
\text { jantares, almoços e } \\
\text { eventos, e doação de } \\
\text { presentes. }\end{array}$ & $\begin{array}{c}\text { De } 3 \text { a } 6 \text { visitas por ano } \\
\text { para a China. }\end{array}$ & $\begin{array}{l}\text { Não há muito } \\
\text { investimento (nem } \\
\text { sempre tem o retorno } \\
\text { esperado). }\end{array}$ \\
\hline Benefícios & $\begin{array}{l}\text { Acesso a informações } \\
\text { sobre o mercado } \\
\text { chinês, fortalecimento } \\
\text { das redes de contato, } \\
\text { aumento da } \\
\text { lucratividade, "cortar } \\
\text { caminhos". }\end{array}$ & $\begin{array}{l}\text { Indicação da empresa, } \\
\text { melhora da reputação, } \\
\text { melhora da imagem, } \\
\text { aumento da confiança. }\end{array}$ & $\begin{array}{l}\text { Comprometimento dos } \\
\text { fornecedores, } \\
\text { cumprimento dos } \\
\text { prazos e melhor } \\
\text { negociação de preço. }\end{array}$ & $\begin{array}{l}\text { Comprometimento dos } \\
\text { fornecedores. }\end{array}$ \\
\hline Dificuldades & $\begin{array}{l}\text { Perda de timing nas } \\
\text { operações de serviços. } \\
\text { Custo e tempo para } \\
\text { agilizar os trâmites } \\
\text { legais são maiores sem } \\
\text { guanxi. }\end{array}$ & $\begin{array}{c}\text { Perda de timing nas } \\
\text { operações de serviços. } \\
\text { Qualidade do serviço e } \\
\text { da empresa é mais } \\
\text { importante que o } \\
\text { guanxi. }\end{array}$ & $\begin{array}{c}\text { Falta de } \\
\text { comprometimento com } \\
\text { a qualidade dos } \\
\text { produtos e atraso no } \\
\text { envio das mercadorias. }\end{array}$ & $\begin{array}{l}\text { Vulnerabilidade às } \\
\text { intempéries do } \\
\text { mercado. }\end{array}$ \\
\hline
\end{tabular}

Fonte: Elaborado pelos autores

Guanxi significa relacionamento interpessoal, troca de favores, rede de contatos, corrupção, crédito e débito de favores. Guanxi não é só pessoal, é familiar e se estende a toda familia. Guanxi e face (mianzi) andam bem juntos. A diferença de relacionamento (networking) e o guanxi está na intensidade, é muito mais intenso. Chega ao ponto de um chinês pedir empréstimo no banco para poder pagar um jantar em retribuição a algum favor recebido. (ENTREVISTADO A1)

Entretanto, o significado de guanxi é mais abrangente do que redes de relacionamento. Com exceção da Empresa T2, todas acreditam que a principal diferença entre guanxi e relacionamento está na intensidade, ou seja, a valorização dos relacionamentos no mercado asiático foi percebida como muito maior se comparado às redes ocidentais. De acordo com o Entrevistado T1, "A gente também tem essa relação de confiança, de minimamente conhecer, mas eu acho que a intensidade é muito maior na China".
Com relação ao grau de importância dado ao guanxi e do investimento das empresas para o seu desenvolvimento, novamente a Empresa T2 demonstrou divergências quando comparada às demais. Todas consideraram alta a importância do guanxi para o sucesso da internacionalização e investem na construção dos relacionamentos, principalmente por meio de visitas aos clientes e fornecedores. Todavia, a Empresa T2 considera moderada a importância, pois nem sempre obtém o resultado esperando com o seu investimento em guanxi. "Não consideramos apenas o guanxi para buscar resultados".

Esta discrepância pode estar relacionada a algumas diferenças de perfil, observadas no Tabela 1. A Empresa T2 é a mais nova das empresas (9 anos) enquanto as demais possuem em média 50 anos desde sua fundação. A T2 possui porte médio-grande, sendo que as outras são de grande porte. E ainda, a 
Tabela 6

O desenvolvimento do guanxi pelas empresas estudadas

\begin{tabular}{|c|c|c|c|c|c|}
\hline \multicolumn{2}{|r|}{ Categoria 3} & Empresa A1 & Empresa A2 & Empresa T1 & Empresa T2 \\
\hline \multirow{3}{*}{$\begin{array}{l}\text { I) } \\
\text { Início }\end{array}$} & $\begin{array}{l}\text { Criação das bases do } \\
\text { guanxi }\end{array}$ & $\begin{array}{l}\text { Contato iniciado } \\
\text { com os clientes já } \\
\text { constituídos pela } \\
\text { empresa na China. }\end{array}$ & $\begin{array}{l}\text { Contato iniciado } \\
\text { por meio de } \\
\text { indicações de } \\
\text { outros parceiros da } \\
\text { empresa. }\end{array}$ & $\begin{array}{l}\text { Contato iniciado } \\
\text { com auxílio dos } \\
\text { agentes coreanos } \\
\text { da empresa. }\end{array}$ & I) Início \\
\hline & $\begin{array}{l}\text { Familiarização (tipo de } \\
\text { atividades realizadas) }\end{array}$ & $\begin{array}{l}\text { Participação em } \\
\text { eventos e visitas } \\
\text { nas empresas pra } \\
\text { se apresentar. }\end{array}$ & $\begin{array}{l}\text { Participação em } \\
\text { eventos e refeições } \\
\text { (jantares e } \\
\text { almoços). }\end{array}$ & $\begin{array}{l}\text { Reuniões seguidas } \\
\text { de refeições } \\
\text { (almoços, jantares } \\
\text { e cafés da manhã) }\end{array}$ & $\begin{array}{l}\text { Dinners with plenty of } \\
\text { baijiu. }\end{array}$ \\
\hline & $\begin{array}{l}\text { Auto-revelação mútua } \\
\text { (reciprocidade) }\end{array}$ & $\begin{array}{l}\text { Depende de como } \\
\text { foi estabelecido o } \\
\text { primeiro contato } \\
\text { (indicação ou não) }\end{array}$ & $\begin{array}{c}\text { Depende do } \\
\text { quanto o cliente } \\
\text { está interessado } \\
\text { em investir no } \\
\text { Brasil. }\end{array}$ & $\begin{array}{l}\text { Reciprocidade } \\
\text { mútua. }\end{array}$ & $\begin{array}{l}\text { Depends on how much } \\
\text { the suppliers interested in } \\
\text { the business. }\end{array}$ \\
\hline \multirow{3}{*}{$\begin{array}{c}\text { II) } \\
\text { Construção }\end{array}$} & $\begin{array}{c}\text { Aumento da qualidade } \\
\text { (como construiu o } \\
\text { guanxi }\end{array}$ & $\begin{array}{l}\text { Branding e } \\
\text { participação em } \\
\text { eventos. }\end{array}$ & $\begin{array}{c}\text { Refeições, } \\
\text { participação em } \\
\text { eventos e troca de } \\
\text { presentes. }\end{array}$ & Visitas periódicas & II) Construção \\
\hline & $\begin{array}{c}\text { Interações expressivas e } \\
\text { instrumentais }\end{array}$ & Ambas & Instrumentais & Ambas & Instrumental \\
\hline & Reciprocidade dinâmica & $\begin{array}{l}\text { Reciprocidade } \\
\text { mútua }\end{array}$ & $\begin{array}{l}\text { Reciprocidade } \\
\text { mútua }\end{array}$ & $\begin{array}{l}\text { Reciprocidade } \\
\text { mútua }\end{array}$ & $\begin{array}{l}\text { Depends on how much } \\
\text { the suppliers interested in } \\
\text { the business. }\end{array}$ \\
\hline \multirow[t]{3}{*}{$\begin{array}{l}\text { III) } \\
\text { Uso }\end{array}$} & $\begin{array}{l}\text { Obtenção de benefícios, } \\
\text { reavaliação do guanxi } \\
\text { (momento insidership) }\end{array}$ & $\begin{array}{l}\text { O cliente chinês } \\
\text { começa a usar a } \\
\text { sua rede guanxi } \\
\text { para benefício da } \\
\text { empresa. }\end{array}$ & $\begin{array}{l}\text { O cliente indica o } \\
\text { escritório para } \\
\text { outras empresas. }\end{array}$ & $\begin{array}{c}\text { O fornecedor } \\
\text { convida clientes } \\
\text { para atividades } \\
\text { expressivas (como } \\
\text { o ano novo chinês) }\end{array}$ & III) Uso \\
\hline & Troca de favores & Houve & Não houve & Não houve & Yes \\
\hline & Equidade de longo prazo & Houve & - & - & Yes \\
\hline
\end{tabular}

Fonte: Elaborado pelos autores

Empresa T2 possui um grande diferencial, que foi a escolha de localização para o seu estabelecimento. Ao contrário das outras que iniciaram no Brasil e internacionalizaram para a China, a Empresa T2 foi fundada na China e depois montou seu escritório de representação no Brasil. A presença cotidiana do entrevistado T2 na China também pode ser uma das razões que justificam a diferença de percepções quanto à importância do guanxi.

Com relação aos benefícios do guanxi, percebemse semelhanças de acordo com o ramo de atuação. Os escritórios de advocacia beneficiaram-se da indicação de clientes, melhoria da imagem e o "corte de caminhos" que o guanxi pode trazer para empresa. Chen (2001) defende que o guanxi deve ser considerado como uma alternativa para suavizar o progresso do negócio dentro de limites legais, o que afetou positivamente as empresas A1 e A2.

A utilidade do guanxi é cortar caminhos e se beneficiar disso. Para um chinês ser promovido, por exemplo, ele precisa ter um bom guanxi, e não necessariamente fazer apenas um bom trabalho. Só sobe na vida quem tem guanxi. (ENTREVISTADO A1)
Para as tradings, o guanxi influenciou no comprometimento dos fornecedores chineses, que passaram a atender os prazos estabelecidos e garantir que os produtos solicitados atendessem os padrões de qualidade solicitados pelos clientes. De acordo com Holm et al (1996), estabelecer relacionamentos com parceiros estrangeiros em estágios iniciais do processo de internacionalização é importante para as empresas que optam pelo baixo comprometimento de ativos no mercado internacional.

Por fim, as dificuldades enfrentadas pela falta de guanxi representam basicamente o oposto dos benefícios, ou seja, o custo e tempo para agilizar os trâmites legais são maiores sem o guanxi (Empresas A1)

Durante a primeira fase, em que os indivíduos se familiarizam uns com os outros buscando uma autorevelação mútua, percebe-se novamente a divergência da Empresa T2 com relação às demais. Enquanto as outras buscaram algum tipo de 
intermediário para iniciar o relacionamento, a Empresa T2 iniciou os contatos via telefone, de forma mais impessoal. Esta postura pode estar relacionada à percepção de que o guanxi não é tão valorizado para o sucesso dos negócios com os chineses. Todavia, este tipo de postura não favorece a construção de confiança, conforme aponta a literatura sobre o assunto.

De forma abrangente, as atividades desenvolvidas na fase inicial foram semelhantes, constituindo-se na participação em eventos, almoços e jantares. O resultado da familiarização inicial pode ser verificada no grau de auto revelação mútua, ou seja, o quão recíproca foi a motivação em estabelecer a base do relacionamento. No caso da Empresa T2, a motivação dos chineses estava relacionada ao grau de interesse no produto ou serviço oferecido. Já para a Empresa A1, a reciprocidade dependeu da forma como originou-se o contato, ou seja, se era um desconhecido ou alguém indicado por uma pessoa de confiança.

De acordo com Chen e Chen (2004), a reciprocidade é um complemento essencial para a iniciativa de auto-revelação, e possui grande influência na criação das bases do guanxi. Neste sentido, a única empresa que obteve reciprocidade mútua no início foi a T1, que teve o auxílio de agentes coreanos da empresa no contato inicial com os chineses.

$\mathrm{Na}$ segunda fase, a construção do guanxi, o objetivo é estabelecer a confiança mútua e o afeto para construir um guanxi de qualidade (CHEN; CHEN, 2004). Nos escritórios de advocacia, o guanxi foi construído por meio da participação em eventos e jantares. Nas tradings, investiu-se em visitas periódicas aos fornecedores para estabelecer a confiança e afeto no relacionamento.

Todas realizaram atividades instrumentais, mas apenas a A1 e T1 investiram em atividades expressivas. Este tipo de atividade tem mais chances de estabelecer a confiança e o afeto, pois são atividades de cunho mais pessoal do que profissional. É interessante ressaltar que estas atividades ocorreram com as empresas que acreditam na importância do guanxi e que utilizaram intermediários para o contato inicial. Isto pode ter contribuído para ocorrência de atividades expressivas.
Todas as empresas, com exceção novamente da T2, acreditam que nesta fase a reciprocidade foi mútua, ou seja, ambos estavam abertos ao estabelecimento do guanxi. A pouca importância e a falta de investimento para o desenvolvimento do guanxi pode ter sido a causa da falta de reciprocidade na empresa $\mathrm{T} 2$.

A terceira e última fase de desenvolvimento é caracterizada pelo uso do guanxi, sendo esta etapa marcada pela troca de favores regulada pelo princípio da equidade de longo prazo (CHEN; CHEN, 2004). Mas antes é preciso saber se de fato a empresa faz parte do guanxi do seu cliente ou fornecedor chinês. É o momento de insidership, em que se começa a ser beneficiado pelas vantagens das redes de relacionamentos. Neste caso, cada empresa teve uma experiência diferente, não havendo um padrão de comportamento. A troca de favores ocorreu apenas nas empresas A1 e T2, sendo que ambas acreditam ser este o principal combustível para manter e fortalecer o guanxi. Um exemplo de troca de favores foi citado por um dos entrevistados.

\begin{abstract}
Uma vez, um cara (chinês) atropelou uma mulher enquanto ia me buscar no trem, e deu dinheiro pra ela ficar quieta e não contar pro chefe dele. Não tem regra quanto a quem começa oferecendo o favor. A retribuição do favor pode ser de várias maneiras (presentes, dinheiro, convite pra eventos restritos). A expectativa é que a retribuição seja no mínimo igual ou melhor. (ENTREVISTADO A1)
\end{abstract}

Com relação ao alinhamento entre as experiências das empresas no desenvolvimento do guanxi e o modelo de Chen e Chen (2004), percebe-se que as atividades realizadas pelas empresas $\mathrm{A} 1$ e T1 vão mais ao encontro do modelo do que das empresas A2 e T2. Ambas (A1 e T1) iniciaram o contato por meio de intermediários, realizaram atividades instrumentais e expressivas e ainda tiveram a reciprocidade mútua no estabelecimento da relação. Na empresa A1, ainda houve a troca de favores como meio de fortalecer o guanxi. No caso da A2 e T2, o alinhamento foi um pouco menor.

Nos resultados fica evidente que o modelo desenvolvido por Chen e Chen (2004) demonstra que as atividades desenvolvidas no início, construção e uso do guanxi estão interligados numa conotação de causa-efeito. As atividades desenvolvidas no início tem impacto no uso.

É importante ressaltar que ambos os entrevistados comentaram sobre a supervalorização dada ao guanxi pelos estrangeiros e que possuem 
certa cautela quando se trata do aprofundamento destas relações. Isto pode ser constatado pela realização de atividades apenas instrumentais e a baixa reciprocidade mútua.

\section{Considerações Finais}

Considerando a análise dos casos e o referencial teórico, foi possível chegar a algumas conclusões. A diferença entre guanxi e as redes de relacionamentos está na intensidade, sendo a lógica de funcionamento para desenvolver relações inter-organizacionais e para desenvolver guanxi bastante semelhantes. A questão da confiança e da reciprocidade, por exemplo, está presente em ambas as abordagens. A principal diferença, que se justifica pela história e cultura dos países asiáticos, está na intensidade e valorização que os chineses dão aos relacionamentos. $\mathrm{O}$ grau de dependência entre a vida do indivíduo e a sua rede de relacionamentos é consideravelmente maior do que nas culturas ocidentais, que possuem traços mais individualistas, ao contrário dos asiáticos que são mais coletivos. Todavia, a base do relacionamento, que é a confiança, está em presente tanto no guanxi quando nas networks.

Perceberam-se também algumas convergências de percepções quanto ao guanxi devido o seu ramo de atuação (escritórios de advocacia e tradings). As situações enfrentadas decorrentes da liability of outsidership são semelhantes, assim como os benefícios gerados pelo guanxi e a importância dada a ele. Todavia, a construção do guanxi não apresentou muitas semelhanças. A forma de desenvolvê-lo está mais relacionada com o grau de importância dado a ele do que do ramo de atuação da empresa.

Mesmo conscientes de que a troca de favores é o combustível para desenvolver o guanxi, as empresas brasileiras ainda tem receio com esta prática. Percebeu-se que ainda há uma barreira cultural por parte dos brasileiros quanto à troca de favores com os chineses. Geralmente é uma política da empresa não promover este tipo de prática, e às vezes não é permitido nem a troca de presentes. Esta é uma importante questão a ser adaptada quando o assunto é fortalecer os negócios com a China.

Assim como o guanxi, a face (mianzi) foi citada pelos entrevistados como um aspecto extremamente importante na China. De nada adiantará investir anos desenvolvendo e fortalecendo o guanxi se a face for perdida. Esta relação de status e reputação moral é uma forma de auto-imagem e status social aprovado (HWANG, 1987). Qualquer estrangeiro que não tenha conhecimento das boas etiquetas e normas de relacionamento na China pode perder mianzi facilmente, e consequentemente prejudicar a construção do guanxi, ou ainda perde-lo completamente.

Com relação às contribuições teóricas deste estudo, entende-se que foi possível aumentar o conhecimento empírico sobre liability of outsidership e guanxi na realidade das empresas brasileiras, além de testar o modelo teórico de Chen e Chen (2004). Além da relevância científica deste estudo, acreditase que o conhecimento sobre a experiência de empresas brasileiras do setor de serviços no desenvolvimento do guanxi pode auxiliar na definição de estratégias de internacionalização de outras empresas, com prioridade para aquelas que desejam estabelecer-se na China.

Para estudos futuros, sugere-se a exploração deste tema de forma a privilegiar, principalmente, em abordagens descritivas, uma vez que há diversos modelos teóricos publicados na literatura internacional. Além disso, sugere-se compreender o desenvolvimento do guanxi em outros tipos de setores e ramos de atuação, para fins de comparação entre as percepções de cada empresa, e desenvolver uma melhor diferenciação entre os benefícios do uso de networks e guanxi.

\section{Referências}

- $\quad$ AHARONI, Y. The foreign investment process. Boston, MA: Division of Research, Graduate School of Business Administration, Harvard University, 1966.

- BARDIN, L. Análise de Conteúdo. Lisboa: Edições, 70 p. 2010

- BELL, D. Guanxi: a nesting of groups. Wenner-Gren Foundation for Anthropological, v. 41, n.1, p. 133-138, 2000

- CARNeIRO, J.; DIB, L. A. Avaliação comparativa do escopo descritivo e exploratório dos principais modelos de internacionalização de empresas. Revista Eletrônica de Negócios Internacionais da ESPM, v. 2, n. 1, p. 1-25, 2007.

- CEBC - Conselho Empresarial Brasil China, 2012. Empresas Brasileiras na China: presença e experiências. Junho, $2012 . \quad$ Disponível em: http://www.cebc.org.br/sites/default/files/pesquisa_pr esenca_das_empresas_brasileiras_na_china__presenca_e_experiencias.pdf. Acesso em: 31/10/2015. 
- CHEN, M. Asian management systems: Chinese, Japanese and Korean styles of business. 1st ed. London: Cengage Learning Emea, 1995.

- CHEN, X. P.; CHEN, C. C. On the intricacies of the Chinese Guanxi: a process model of Guanxi development. Asia Pacific Journal of Management, v. 21, n. 3, p. 305-324, 2004. DOI: 10.1023/B:APJM.0000036465.19102.d5

- CYERT, R.; MARCH, J. A behavioral theory of the firm. New York: Prentice Hall, 1963.

- DUNNING, J. The eclectic paradigm of international production: a restatement and some possible extensions. Journal of International Business Studies, v. 19, n.1, p. 1-31, 1988.

- ERIKSSON, K.; JOHANSON, J., MAJKGARD, A.; SHARMA, D. D. Experiential knowledge and cost in the internationalization process. Journal of International Business Studies, v. 28, n. 2, p. 337-360, 1997.

- FAIRBANK, J.K, GOLDMAN, M. China - Uma Nova História. Porto Alegre: L\&PM, 2007.

- Fleury, A. C. C.; FleURY, M. T. L. Multinacionais Brasileiras: competências para a internacionalização. São Paulo: FGV, 2012.

- FleURY, M. T. L.; FLEURY, A. C. C. Internacionalização e os países emergentes. São Paulo: Atlas, 2007.

- GIL, Antônio Carlos. Como elaborar projetos de pesquisa. 4. ed. São Paulo: Atlas, 2009.

- HAIHUA, Z.; BAKER, G. Think like Chinese. Sydney: The Federation Press. 2008.

- HOLM, D. B.; ERIKSSON, K.; JOHANSON, J. Business Networks and Cooperation in International Business Relationships. Journal of International Business, v. 27, n. 5, p. 1033-1053, 1996.

- HWANG, K. K. Face and favor, the Chinese power game. The American Journal of Sociology, v. 92, n. 4, p. 944-974, 1987. DOI: 10.1086/228588

- JOHANSON J.; VAHLNE J.E. The internationalization process of the firm: a model of knowledge development and increasing foreign market commitments. Journal of International Business Studies, v. 8, n. 1, p. 23-32, 1977.

- JOHANSON J.; VAHLNE J.E. Business relationship learning and commitment in the internationalization process.
Journal of International Entrepreneurship, v. 1, n. 1, p. 83-101, 2003.

- jOHANSON J.; VAHLNE J.E. The Uppsala internationalization process model revisited-from liability of foreignness to liability of "Outsidership, Journal of International Business Studies, v. 40, p. 4111431, 2009.

- $\quad \mathrm{KAO}, \mathrm{C}$. Personal trust in the large businesses in Taiwan: a traditional foundation for contemporary economic activities. In G. Hamilton (Ed.). Business networks and economic development in East and Southeast Asia. Hong Kong: Centre of Asian Studies, U. of Hong Kong, 1991.

- KARIMIBABAK, P.; SINCLAIR, C. Liability of outsidership: how do companies overcome liability of outsidership? Bachelor Thesis. University of Gothenburg, School of Business, Economics and Law, Sweden, 2011.

- $\quad$ LUO, Y. Guanxi and business. Singapore: World Scientific Publishing, 2001.

- MATHEWS, J. Dragon multinationals: new players in the 21st century. Asia-Pacific Journal of Management, v. 23, n.1, p. 2-27, 2006. DOI: 10.1007/s10490-006-6113-0

- OeSTERLE, M.-J.; Wolf, J. 50 Years of Management International Review and IB/IM Research. Management International Review, v. 51, v. 6, p. 735-754, 2011. DOI: 10.1007/s11575-011-0106-z

- PENROSE, E. T. The theory of the growth of the firm. Oxford: Basil Blackwell, 1959

- SChWEIzer, R.; VAHLNE J.E; JOHANSON, J. Internationalization as an entrepreneurial process. Journal of International Entrepreneurship, v. 8, n. 4, p. 343-370, 2010. DOI: 10.1007/s10843-010-0064-8

- $\quad$ SILVA, M. G. ROCHA, A. M.; FIgUeredo, O. Medindo o construto da distância psíquica. E\&G Economia e Gestão, v. 7, n. 14, p. 1-178, 2007

- STANDIFIRD, S. S. Using Guanxi to Establish Corporate Reputation in China. Corporate Reputation Review, v. 9, n. 3 , p. 171-178, 2006. DOI: 10.1057/palgrave.crr.1550026

- YANG, M. M. Gifts, favors, and banquets: the art of social relationships in China. Ithaca, NY: Cornell University Press, 1994.

\section{Sobre os Autores}

- Janaina Mortari Schiavini é Doutoranda em Administração pela Universidade do Vale do Rio dos Sinos - Unisinos, São Leopoldo, RS, Brasil.E-mail: janaina.schiavini@gmail.com

- Flavia Luciane Scherer é Doutora em Administração. Professora Associada da Universidade Federal de Santa Maria-UFSM, Santa Maria, RS, Brasil.E-mail: flaviascherer@globo.com 


\title{
Overcoming liability of outsidership in China: The experience of Brazilian companies in developing Guanxi
}

\author{
Janaina Mortari Schiavini ${ }^{A}$ and Flavia Luciane Scherer ${ }^{B}$ \\ ${ }^{\text {A }}$ Universidade do Vale do Rio dos Sinos - Unisinos, São Leopoldo, RS, Brazil. \\ ${ }^{B}$ Universidade Federal de Santa Maria - UFSM, Santa Maria, RS, Brazil.
}

\begin{tabular}{l}
\hline ARTICLE DETAILS \\
\hline Article history: \\
Received 25 August de 2014 \\
Accepted 01 July 2015 \\
Available online in 19 December 2015 \\
Double Blind Review System \\
Scientific Editor \\
Felipe Mendes Borini \\
\hline Keywords: \\
Internacionalization \\
Liability of Outsidership \\
Guanxi \\
Networks \\
China \\
\hline
\end{tabular}

\begin{abstract}
In light of discussions on corporate internationalization, a theoretical approach advocates that the main barriers to internationalization are related to the burden of being outside international relationship networks, that is, so-called liability of outsidership. Given China's relevance to Brazil and the complexity of that country's business relations (guanxi), this study aims to investigate how Brazilian companies operating in China develop guanxi as a means of overcoming liability of outsidership, based on Chen and Chen's theoretical framework (2004). A descriptive and qualitative study was conducted analyzing multiple cases in four Brazilian companies from the services sector with offices in China. Data were collected through semi-structured interviews. Data were treated by content analysis using NVivo 8.0 software. The results identified the motives behind internationalization to China, the difficulties encountered due to the liability of outsidership, the significant benefits of guanxi, and activities carried out in order to develop it. This study is expected to contribute to generating knowledge on the internationalization of companies to China.
\end{abstract}

C 2015 Internext | ESPM. All rights reserved! 